\title{
10 Parliament and public participation in Kenya
}

\author{
The case of the Wildlife
}

Conservation and Management

Act 2013

\author{
Mine Pabari, Yemeserach Tessema, Amina Abdalla, \\ Judi Wakhungu, Ahmed Hassan Odhowa \\ and Ali Kaka
}

\section{Summary}

This chapter explores the role of Parliament in policy making through citizen engagement and public participation, drawing on experiences from the review and enactment of Kenya's Wildlife Conservation and Management Act 2013. The chapter identifies and discusses the particular contextual factors that enabled and/or hindered the use of evidence generated through the public participatory processes. It concludes by providing lessons and reflections for strengthening the involvement of the wider public in policy making in Kenya and beyond.

\section{Introduction}

In 2013, problems in managing the wildlife sector in Kenya came to a head. The levels of poaching had been steadily escalating over the years and Kenya, together with Tanzania and Uganda, was being heavily criticised by the international community for not having stringent enough laws to curb the crimes. At the same time, the legislation, developed in 1976 and amended in 1989, was not aligned with the country's new constitution which came into effect in 2010. There was therefore a sense of urgency across the country about putting in place legislation appropriate to the situation and needs of the country's wildlife sector.

The Wildlife Conservation and Management Act 2013 (WCMA 2013) has, as its long title, An Act of Parliament to Provide for the Protection, Conservation, Sustainable Use and Management of Wildlife in Kenya and for Connected Purposes (Republic of Kenya (RoK), 2014). Approved by Parliament in December 2013, the Act came into force on 10 January 2014, replacing the Wildlife Act, Cap 396 of 1976. WCMA 2013 was realised through an intense process of citizen engagement and public participation.

This chapter examines the role of a parliamentary body leading public participation in policy making in Kenya, using the case of WCMA 2013. The chapter explores the rationale behind citizen engagement as the source of evidence 
used and identifies critical factors that influenced the process and outcomes of this engagement within the political and social context.

The methodology for this chapter is a case study using data drawn from a literature review and interviews. The literature reviewed covered published and unpublished documents such as correspondence, published articles, Hansard reports from the Kenyan Parliament and thematic reports, among others. Semi-structured interviews were conducted in November 2018 with 22 key informants, drawn from government institutions, non-governmental organisations (NGOs), community-based organisations (CBOs) and private individuals directly and indirectly involved in the WCMA 2013 process. The interviewee list was informed by a review of the literature and drew from interviews with policy makers involved in driving the review process. Referrals, or the snowball sampling method, were also used.

\section{The context}

\section{A turbulent history}

Wildlife management in Kenya is a highly charged and emotional topic, with tensions that can be traced as far back as Kenya's independence in 1963.

Formal legislation around wildlife in Kenya began under colonial rule, with the first hunting regulations dating back to 1898. During the colonial period, a number of protected areas were established on lands formerly used and inhabited by communities. Many communities, especially pastoralists, were dispossessed of livestock dispersal areas, seasonal migration routes and, perhaps most importantly, watering points. This caused deep resentment and ambivalence towards protected areas (E. Barrow and Fabricius, 2002). These systems have been described as state-driven, top-down management of protected areas (E. G. C. Barrow et al., 2000; Kabiri, 2010a; Western, 2000). Following independence in 1963, Kenya maintained many of the systems created by the colonial regime.

The post-colonial Sessional Paper No. 3, Statement on the Future of Wildlife Policy in Kenya (Kenya, 1975), remains the guiding policy document for wildlife management to date, and was put into force by the Wildlife Conservation and Management Act (1976), Cap 376 (Kabiri, 2010). The Wildlife Conservation Act of 1976 allowed landowners to manage and receive payments from commercial hunting. However, this was quickly overturned with a ban on consumptive utilisation in 1977, said to have been driven by animal rights groups and the tourism industry (Nelson, 2010). This policy decision has been a central stumbling block in the various attempts that have taken place over the years to devolve authority over wildlife (Ibid.). Since then there have been multiple debates, often with highly polarised views stemming from very different conservation ideologies. A major criticism of the natural resources legislation in Kenya has revolved around exclusion of local communities, which has had a negative impact on the conservation of Kenya's environmental resources, including its wildlife.

The 1989 Wildlife (Management and Conservation) Amendment Bill established a parastatal organisation under the Ministry of Tourism and Wildlife, the 
Kenya Wildlife Service (KWS), to conserve and manage Kenya's wildlife. Prior to the formation of KWS, the government exercised centralised authority and a top-down approach to wildlife protection and management, with minimal involvement of non-state actors. With the introduction of KWS, a number of alternative management models were introduced aimed at enabling greater involvement of communities in wildlife management (Anyonge-Bashir and Udoto, 2012; Western et al., 2015) Like many government institutions, however, KWS has struggled with inadequate funding and instability in leadership and vision and has undergone multiple changes over the years.

Limitations in government's capacity to manage wildlife gave room for other stakeholders to engage in conservation of wildlife resources around the country. NGOs, with the support of development partners, have made an important contribution to promoting different types of wildlife management regimes that cater for wildlife outside of protected areas. They have also been engines in Kenya's wildlife policy processes at all stages, either individually or through formal and informal alliances and networks.

The involvement of local communities and the private sector in wildlife management has historically been localised around communally or privately owned areas, which later came to be known as 'conservancies'. 1 These were areas set aside by individuals or communities to conserve endangered species or increase benefits from wildlife through tourism, often with the support of NGOs and/or privately owned companies (Kenya Wildlife Conservancies Association, 2016). In April 2013, the Kenya Wildlife Conservancies Association (KWCA) was established to leverage and strengthen the voices of community groups around the country. Since its establishment, KWCA has been a key player in legislative review processes affecting the sector and was an active participant in the WCMA 2013 review process.

\section{Previous attempts to revise legislation of the wildife sector}

In 2006 a technical steering committee comprising representatives of different stakeholder groups reviewed both the government's policy towards wildlife described in Sessional Paper No. 3 of 1975, Statement on Future Wildlife Management Policy, and the Wildlife Conservation and Management Act, Cap 376. Funding for this was provided by the United States Agency for International Development (USAID) through the World Wildlife Fund (WWF). The technical steering committee conducted widespread stakeholder consultations and reviewed available literature and research, particularly from southern African countries, the US and Australia. There was a perception that local studies were not good enough at the time. Despite this limitation, the committee felt that the two documents that resulted from the extended consultative process were a fair representation of people's aspirations for the wildlife sector. In 2007, the draft Wildlife Policy and Act were finalised and submitted to the Ministry of Wildlife, Environment, Water and Natural Resources (MEWNR). Unfortunately, the timing coincided with a fraught general election year, and the document was shelved for future action. 
In 2010, another NGO, the East Africa Wildlife Society (EAWLS), also secured funding from USAID through the NGO, Pact Kenya, to revise the draft Policy and Act in collaboration with the ministry and KWS. This process was carried out by a technical task force comprising experts in the sector, and primarily involved expert review and input with a final stakeholder review and validation meeting. In January 2012, the team submitted the revised document to the MEWNR. The ministry approved the draft bill submitted by the technical committee and published it in the Kenya Gazette in July 2013 for public input. The draft bill drew many responses, and individuals interviewed for this case study said that the version that eventually reached Parliament in 2013 was missing critical sections. Multiple interviewees reported that alterations were made driven by individual ulterior motives. Concerns raised around the lack of clear and transparent mechanisms and processes between technical drafting and presentation to Parliament led to both documents being shelved.

\section{Catalysts of change}

In 2010, Kenya adopted a new constitution which was a critical turning point for the country on multiple fronts. Of particular relevance to this case are (1) the emphasis placed on sustainable development (Article 10) and the environment (Article 69); (2) the changes the constitution brought about in the roles of Parliament (Article 94) (3) and the involvement of the public in policy making.

The strengthened role of the legislature in policy making is aptly described by one of the interview respondents:

One of the things that the 2010 Constitution did was move to a presidential system of government. In a presidential system of government, the executive proposes, and the legislature takes the lead in a very hands-on manner to midwife the policy process without somebody breathing on it. We used to have a different system of government which was a hybrid where some members of the executive were in parliament. So, this was a parliamentarydriven process once the document had been tabled in the house.

(Respondent 14 - Government)

Public participation is a key pillar of the 2010 Kenya Constitution. The National Assembly defines it as 'the process of interaction between an organisation and the public with the aim of making an acceptable and better decision' (The Clerk of the National Assembly, 2017).Various articles of the 2010 Kenya Constitution guarantee public participation. Article 118(1)b, for example, requires Parliament to 'facilitate public participation and involvement in the legislative and other business of Parliament and its committees'. Article 118(1)(a) further provides that Parliament 'conducts its business in an open manner and its sittings and those of its committees shall be open to the public'. Relevant committees of Parliament facilitate public participation through mechanisms which include, but are not limited to, petitions, submissions of memoranda, public hearings, consultations with relevant stakeholders and consultations with 
experts on technical subjects. The 2010 constitution specifically guarantees public participation in the environment sector through Article 69(1) which reads as follows: 'The State shall - (d) encourage public participation in the management, protection, and conservation of the environment'.

The years leading up to 2013 were marked by a spike in wildlife poaching, with elephant and rhino populations being decimated in many parts of Africa. In March 2013 the Convention on International Trade in Endangered Species (CITES) identified Kenya, Tanzania and Uganda as members of the 'Gang of 8' countries fuelling the illegal trade in ivory. The three countries were heavily criticised for not having stringent enough laws to curb the escalating wildlife crime. ${ }^{2}$ In Kenya, the law at the time treated poaching as a 'petty crime' and in the words of one of the interview respondents, 'almost offered incentives to poach' (Respondent 12 - Government). The government was therefore under significant pressure from within and outside the country to do its part to stop the global illegal trade.

\section{Revising the Act}

\section{The journey}

The first elections held under the new constitution took place in March 2013. As one of the first Acts of the new Parliament, the journey of the WCMA 2013 pioneered the provisions for public participation in the legislative process.

In 2013, the MEWNR submitted a bill to Parliament for review and debate. The Act was then charged to the Departmental Committee on Environment and Natural Resources (DCENR), which led the citizen engagement process. The DCENR is a parliamentary committee, comprising 29 members of Parliament, which is mandated to review all legislation relating to climate change, environment and natural resources.

The DCENR was supported by Parliamentary Research Services (PRS). PRS, as of 2019, comprised of 30 researchers. The unit supports Parliament by providing background information, briefings, policy analysis and reports, among others, to support evidence-based legislation and decision making by members of Parliament. PRS also provides support to house committees, such as the DCENR, which includes receiving, collating and analysing input from the public (Respondent 1 - Government).

In September 2013, responses from the public to the draft bill submitted in 2012 were discussed in a retreat convened by the DCENR together with the ministry, led by the Cabinet Secretary.

As required under Article 118 of the constitution, the DCENR invited members of the public, through the national newspapers, to submit any representations they may have on the Act. Responses from the public were received through written proposals and telephone calls to PRS. Proposals came from several organisations including community coalitions and associations such as the KWCA, NGOs and members of the public. Written submissions referred to published research, grey literature and individual experiences. The PRS received, collated, and analysed written and oral proposals from stakeholders 
and provided the interface between the DCENR and stakeholders (Republic of Kenya (RoK), n.d.). Submissions made to DCENR ranged from proposals aimed at strengthening the institutional frameworks (such as including community representatives on the KWS Board of Trustees) to creating provisions (such as the provision of incentives for wildlife management as a land use).

The DCENR met seven times to discuss the draft bill, including two meetings where stakeholders were given the opportunity to present their proposals and arguments in person. In addition, the DCENR also invited individuals representing opposing sides of the wildlife consumptive utilisation debate to attend a closed-door session with committee members.

At a second reading in Parliament, the committee normally simply presents a report on the process to date. In this case, the committee presented both the report as well as proposed amendments to the Act. This then allowed for discussion and debate within Parliament and resulted in additional amendments which were incorporated by the chairperson. A decision on all amendments was taken at the third reading of the bill, presented to the Committee of the Whole comprising all the Members of Parliament. The Act was approved by Parliament in December 2013 and came into force on 10 January 2014, replacing the Wildlife Act, Cap 396 of 1976.

\section{Amendments to the Act}

There was a broad consensus among interview respondents that, given the poaching crisis, the Act needed to be passed urgently and that it was sufficiently adequate to do so. However, it was also recognised that there were flaws in the legislation and, to the credit of the DCENR, the Committee monitored the performance of the Act with periodic input from PRS. Matters flagged by PRS were transmitted to the ministry to give their official response to the committee.

PRS used information available in mainstream and social media, as well as information provided directly by stakeholders engaged in the earlier consultation processes. PRS compiled a brief on poaching trends, which triggered an investigation by the committee on the unrelenting poaching menace in the country. Also, as part of the WCMA 2016 amendment process, the DCENR convened breakfast meetings with stakeholders and other relevant government bodies, including the judiciary, to discuss specific amendment proposals. In addition, shortly after the passage of WCMA 2013, the NGO, Africa Network for Animal Welfare (ANAW), the Judiciary Training Institute and Kenyans United Against Poaching (KUAPO) initiated the formation of a task force to amend the bill. The task force worked on proposed amendments to the bill and presented the revised document to DCENR at a meeting in December 2014.

The DCENR chairperson followed up with due process of a first reading at Parliament, releasing the call for public input and participation. In response to its call for public participation, the DCENR received proposals from a number of civil society organisations. Unfortunately, after the first reading, the process stalled as the country underwent a general election and Parliament 
was dissolved. This reset the approval process and the amendment bill had to undergo the entire development procedure from the beginning. Initially there was reluctance to restart the process until the new wildlife policy was in place. However, the process was restarted, and certain sections of the WCMA 2013 were amended through the Miscellaneous Amendment Bill in December 2018. The long road to the enactment and amendment of the WCMA 2013 is summarised in Figure 10.1.

\section{Outcomes}

Case study respondents unanimously recognised that simply bringing the Act into being after 16 years was an accomplishment. Perhaps one of the greatest achievements of the process was the strong sense of ownership across the diverse group of stakeholders - from the different arms of government to NGOs and CBOs and individual members of communities living with wildlife. This notwithstanding, the shortcomings of the Act are also heavily criticised, and the country continues to grapple with developing legislation that balances conserving wildlife with ensuring that the sector contributes positively to livelihoods and the economy in what is, today, a highly dynamic and complex macro environment.

Some of the most significant outcomes of the review process, as identified by interview respondents, are discussed in the next subsection.

\section{Instrumental use}

The Act comes into force and reflects citizen views on new directions for the sector: Interview respondents were unanimous that the engagement of a wide range of citizens played a critical role in ensuring that the Act was passed this time around, and that the Act reflected many of the submissions and inputs made by contributing stakeholders. Fundamental changes in the Act that emerged from the review process are as follows:

- Kenya Wildlife Service: In addition to enhancing KWS's role and mandate, the Act called for a significant restructuring of KWS's powerful board of trustees. The Act requires the board to be more representative of the sector by including representatives of wildlife, finance and county governments as well as NGOs, community-managed areas and privately managed wildlife areas. In addition, for the first time, the board is required to ensure that community representative include both men and women. The composition of the board at the time of writing this case study met these requirements.

- Compensation: Compensation for destruction of property, injury, and loss of life due to human-wildlife conflict was always contentious and was inadequate to non-existent prior to the Act. For example, the Act designates monetary compensation for the loss of human life at KES 5 million ( USD 50,000 ), whereas it was previously pegged at KES 200,000 ( USD 2,000). The Act also seeks to streamline the bureaucratic process for accessing 
176 Mine Pabari et al.

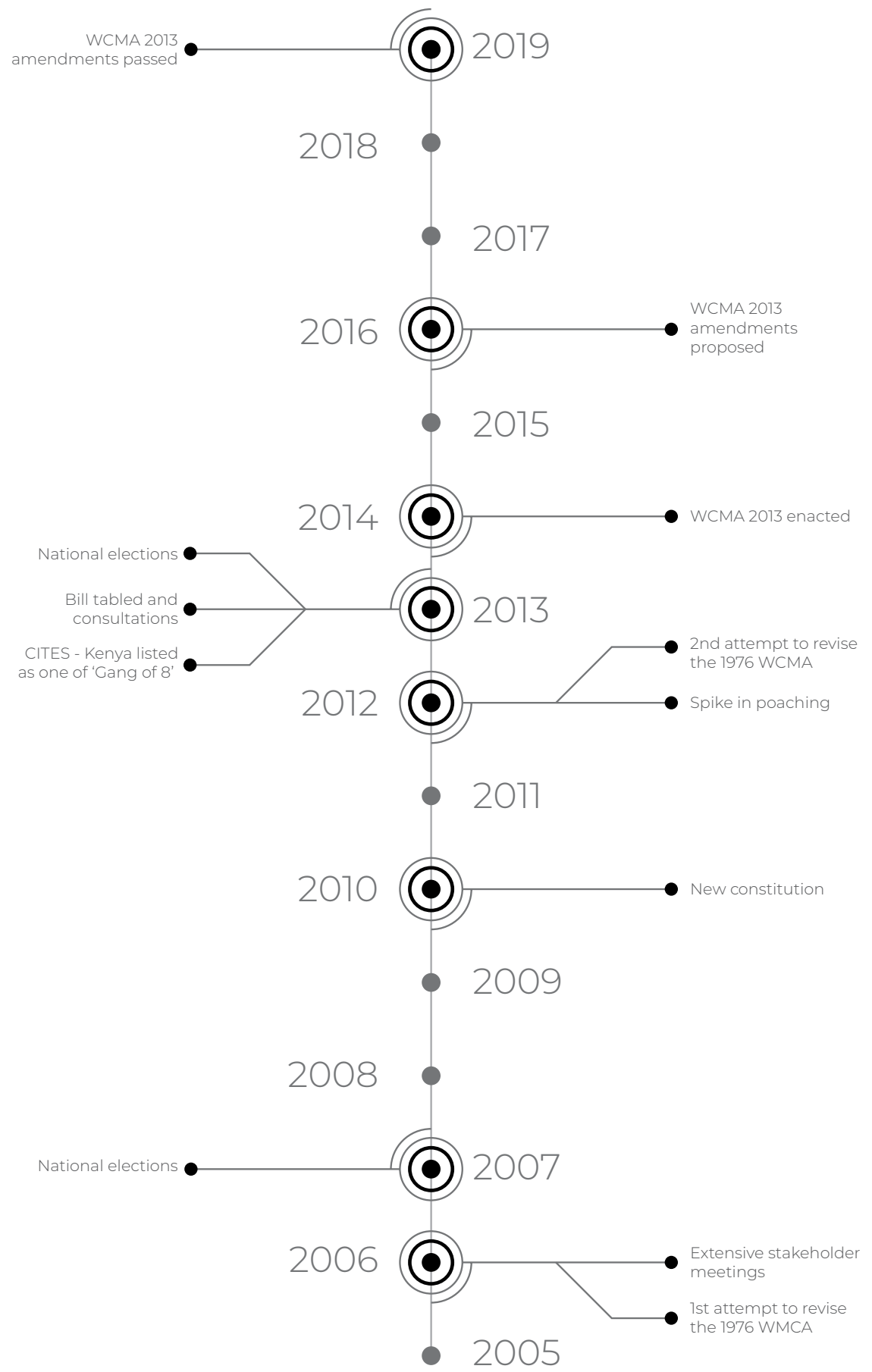

Figure 10.1 The WCMA 2013 journey

Source: Author generated. 
compensation and for the disbursing of funds. However, the operationalisation of monetary compensation has met challenges, including inadequate funds to meet demand (also discussed under Barriers to Effective Public Participation).

- Offences and penalties: Prior to the Act, penalties for wildlife crime were minimal and provided little deterrent to offenders. The Act introduced more stringent penalties, particularly for killing wildlife categorised as endangered by CITES, including hefty fines and significant time behind bars. An example penalty is KES 20 million ( USD 200,000) or life imprisonment for killing a Category A species (e.g. elephant and rhino). According to a study carried out by the NGO, Wildlife Direct, following the enactment of the Act 'substantial improvement in the processes and outcomes of wildlife crime cases' was realised (Dr. Paula Kahumbu et al., 2017, p. 8).

- Incentives and benefit sharing: The perceived lack of tangible benefits from wildlife to landowners and communities has been counterproductive to long-term conservation objectives. As a significant percentage of wildlife resides outside of protected areas, communities that bear the costs of wildlife on their lands have been pushing for enhanced benefits derived from consumptive and non-consumptive use of wildlife. Thanks to the Act, wildlife conservation is now a recognised option for land-use management. ${ }^{3}$ Landowners can apply for licences to derive benefits ranging from wildlife tourism to game farming. At the time of writing this case study, the ministry was looking to carry out further research into practical and feasible ways to improve benefit sharing and community engagement.

\section{Process use}

Experiences used to strengthen tools and skills for public participation in government: The lessons from the WCMA 2013 review were used to develop and strengthen national processes for public participation. A format for stakeholder participation was developed, drawing on the WCMA 2013 experience, which was adopted by DCENR, and later by the National Assembly. The former chair of the DCENR worked with Parliament and other bodies to incorporate the developed tools to inform future committees. This included input to the development of a 'Committee Management Manual' for the National Assembly and for county assemblies. Guidelines and check lists for good practices developed are being used in training sessions on public participation held regularly at national and local levels.

Rebuilding of trust and relationships between government and civil society: Policy development processes for the wildlife sector had suffered from a lack of legitimacy. Citizen engagement in policy-making processes built relationships between the different actors and stakeholders involved.These relationships were important for credibility, helped the government understand the root causes of the diverse perspectives in the sector and opened up spaces for the creation of mutual agendas. 


\section{Understanding the successes and the challenges}

The constitution made public participation a requirement, but it was not the only driving force. Previous attempts to review the Policy and the Act made it clear that meaningful citizen engagement was critical to the successful revision of the Act by creating greater transparency and therefore minimising the risks of 'political sabotage' (as experienced in the 2010-2013 review process). Perhaps more importantly, there was a strong conviction that the very nature of the sector, with its diversity of stakeholders, interests and ideological positions, demanded public participation. These characteristics, as well as the history of the sector, also made effective participatory processes extremely challenging. It is therefore important to unpack, understand and learn from (1) factors that facilitated and hindered the public participatory processes led by a parliamentary committee; and (2) outcomes that emerged as a consequence.

Wildlife is a resource that belongs to all Kenyans; for us to conserve it, the diversity of all Kenyans must be involved.

(Respondent 12 - Government)

\section{Interventions used to trigger changes necessary for effective public participation}

For the review process to have successfully resulted in the enactment of the Act, with the buy-in and endorsement of stakeholders, a number of changes needed to take place. These included rebuilding trust, increasing levels of support for, and willingness to engage in, public participatory processes. In addition, this involved ensuring that opportunities were created for stakeholders to engage and that they were sufficiently aware of how to utilise these opportunities. Because of the subtle and invisible nature of these elements, understanding how they are realised (and under what circumstances) can be extremely challenging. The interventions used by the DCENR, by other arms of government and by members of civil society that ultimately resulted in these changes, are summarised in Table 10.1 and discussed in further detail after the table.

The timing was ripe for action. Poaching and other crises have always come and gone and hence the pressure from the poaching crisis does not present the totality of the picture. Also, the poaching crisis is a global phenomenon and not uniquely Kenyan.

(Respondent 4 - Non-government)

\section{Factors enabling and hindering participation}

\section{Enabling factors}

Fortuitous circumstances and timing: Two factors, the sense of urgency created by the poaching crises and the constitutional requirement to update the legislation, 
Table 10.1 Use interventions and change mechanisms

\begin{tabular}{|c|c|}
\hline Intervention/strategy employed & Effect and change triggered which enabled use \\
\hline $\begin{array}{l}\text { Dialogue and debates convened by } \\
\text { the DCENR enabled engagement } \\
\text { between sectoral experts (national } \\
\text { and international) and policy makers } \\
\text { using strategic for a, such as breakfast } \\
\text { meetings }\end{array}$ & \multirow{8}{*}{$\begin{array}{l}\text { Over a period of three months, the } \\
\text { DCENR conducted an intense process } \\
\text { of consultation involving seven meetings, } \\
\text { including two stakeholder forums, one- } \\
\text { to-one discussions and a review of several } \\
\text { submissions from the public (Annex 1). } \\
\text { Some of the changes that this process } \\
\text { triggered that ensured the use of evidence } \\
\text { in the review of the Act included: } \\
\text { - Development of relationships and } \\
\text { understanding of one another's perspectives } \\
\text { and realities } \\
\text { Deepened insights and understanding of } \\
\text { sectoral realities and challenges } \\
\text { Packaging of information in a manageable } \\
\text { manner which helped policy makers } \\
\text { understand and relate the evidence to the } \\
\text { specific policy challenges } \\
\text { Increased spaces to ensure that citizens have } \\
\text { equal voice, thereby increasing a sense of } \\
\text { ownership of the process }\end{array}$} \\
\hline $\begin{array}{l}\text { Both the DCENR and civil society } \\
\text { independently convened and facilitated } \\
\text { dialogue, debate and conflict towards } \\
\text { consensus positions }\end{array}$ & \\
\hline $\begin{array}{l}\text { The DCENR created templates and } \\
\text { processes for stakeholder inputs to be } \\
\text { submitted in an organised manner and } \\
\text { in direct response to the Act }\end{array}$ & \\
\hline $\begin{array}{l}\text { Civil society organisations collaborated } \\
\text { with each other to develop joint } \\
\text { submissions }\end{array}$ & \\
\hline $\begin{array}{l}\text { Knowledge brokering roles were played } \\
\text { by PRS and civil society. Examples are: } \\
\text { Proactive identification, outreach and } \\
\text { guidance to civil society and other } \\
\text { organisations to encourage submissions } \\
\text { and share existing data and research } \\
\text { Consolidation and synthesis of } \\
\text { submissions and evidence acquired and } \\
\text { making these available to the DCENR } \\
\text { in a digestible format. This included } \\
\text { generation of draft reports around } \\
\text { specific areas requiring further debate }\end{array}$ & \\
\hline $\begin{array}{l}\text { DCENR created spaces specifically to } \\
\text { generate additional insights around } \\
\text { highly conflictual areas by bringing } \\
\text { together individuals with directly } \\
\text { opposing views to debate them in the } \\
\text { presence of committee members }\end{array}$ & \\
\hline $\begin{array}{l}\text { Proactive outreach and engagement } \\
\text { (particularly with local communities } \\
\text { living in remote wildlife-rich areas) }\end{array}$ & \\
\hline $\begin{array}{l}\text { Closed-door meetings with influential } \\
\text { actors to further enable consensus } \\
\text { building as well as pre-empt the risks of } \\
\text { political sabotage and influence }\end{array}$ & \\
\hline
\end{tabular}

were significant in creating an environment where stakeholders were willing to come to the table and work together to move the legislation forward. It is also important to note that the review process took place well after the elections, which provided a less politically charged environment for decision makers to engage with the evidence presented to them. 
A well-organised civil society with established relationships: The multiple attempts to revise the policy in previous years were far from unproductive. In each of the review processes, members of civil society gathered, or conducted, research around policy matters of specific interest to them. The lobbying, advocacy and debates that took place enabled them to develop their positions and strengthen their arguments over time, as well as to form relationships with like-minded entities and influential actors and institutions. These preparatory actions were all critical in enabling them to respond quickly to the calls for public participation in a collective and organised manner. This was carried out through the preparation of joint submissions and sharing key pieces of research and other forms of evidence with the DCENR. A good example in this regard is the working relationships forged between the judiciary, NGOs (ANAW, KUAPO), KWS (under the ministry), DCENR, and PRS, which led to the proposals that resulted in the WCMA 2016 amendment document.

Representation of key stakeholders in the wider community: While it is recognised that local communities are significant players in the sector, engaging them in policy-making processes is challenging. Many reside in remote areas with limited access to telephones, newspapers and so forth. Additionally, not all communities are organised under well-governed structures. One of the advantages of the legislature leading the process was that having members of Parliament in the DCENR ensured that the views of the communities they represented were included during the review process. The existence of platforms and networks such as KWCA was also instrumental in this regard, as were the relationships NGOs had established through their field-based projects and other initiatives.

Skills, experience and expertise to take advantage of enablers and facilitators: A number of the governmental and non-governmental entities involved were individuals in leadership and management positions that had extensive experience in the sector and in facilitating multi-stakeholder processes and influencing policy. As such, they were able to take advantage of the enabling situation to mobilise and influence.

Effective knowledge brokers: A number of the stakeholders involved had the capabilities and experience to be knowledge brokers. PRS was able to play an important role as 'transmitters, interpreters and synthesisers of information' (Draman et al., 2017, p. 27). NGOs were also well positioned to play knowledge-brokering roles, carrying out studies to gather evidence around particular issues or drawing on existing research and presenting this evidence in a concise format to the committee.

\section{Barriers to effective public participation}

Lack of guidance and regulations for effective participation: Prior to the new constitution, spaces for public participation were limited, and government enjoyed unfettered power. When the WCMA 2013 was being revised, there were no regulations or guidelines in place, and capacity for participation and 
participatory processes was limited. This, coupled with the fact that the process was under immense time pressure, resulted in a number of shortcomings. For example, there was no scoping or analysis to identify stakeholders that needed to be involved, and outreach was only through an English-language newspaper. Calls for participation were only released for a short period with hearings convened only in the capital city. Therefore, it is very likely that representation, and therefore citizen knowledge and views gathered, were incomplete and/or insufficiently balanced. A number of interviewees also felt that the process was rushed with calls for engagement released at the last minute, which did not allow them sufficient time to prepare.

Public participation is good, but it has to be determined what exactly is being sought - quality or quantity of participation. To a certain extent the WCMA process had quantity, but not quality participation. This is partly evident in the scramble to revise parts of the Act beyond its enactment. Lawmakers need to determine the quality of the stakeholders that they engage in policy-making process. Social science can help us determine this. The question of quality does not mean that people have to be formally educated, but they need to be connected to the issues they represent

(Respondent 3 - Non-government)

Resource limitations and consequences for equitable participation and evidence quality: Budgetary resources and the time available to the DCENR was far from adequate. Therefore, the committee relied on individuals and organisations with resources available to them to access and gather evidence and to mobilise and gather views from their networks (particularly local communities). This resulted in questions and concerns around elite capture and the robustness of the evidence that ultimately influenced the contents of the Act.

NGOs in Kenya are driven by a variety of ideological positions in their approach to wildlife management, and the well-funded and organised NGOs often have sway over the type of decisions made by government institutions as these institutions are often weak and lack resources (Kabiri, 2010b; NortonGriffiths, 2010). According to a number of respondents, wrangling for public opinion and legislative backing on either side of the debates (particularly with regards to consumptive utilisation) seems to be mainly driven by NGOs, with both sides claiming to represent the views of communities. Individuals interviewed expressed concern that community groups in wildlife areas adopted the views and ideologies of the dominant NGO in their specific area.

Others felt that the debates were being driven silently by the development partners who were providing financial support to different groups. Government representatives interviewed expressed frustration at being pulled in many directions by powerful NGOs. It was also expressed that, in the absence of a strong government with a clear vision for the wildlife sector and the capacity and wherewithal to implement its priorities, influential local and international 
interest groups would continue to hijack the public participation process. A few respondents suggested that a more strategic approach would be to first build the capacity of government and then engage the public.

There is a continuous focus on working with the big conservation organisations, side-lining smaller ones ... a monopoly within conservation bodies that have direct links to senior government officials. What does this mean for the grassroots organisations?

(Respondent 22 - Non-government)

Public participation has changed due to social media. Many issues are led by urban people who have no idea about the cost of hosting wildlife on land. The loudest voices in consumptive use discussions come from urban centres.

(Respondent 11 - Non-government)

Poor knowledge management and learning culture: Previous processes generated a wealth of citizen views and evidence to inform policy challenges that the sector was grappling with. However, without a mandatory repository and mechanisms for tracking both the decisions and the evidence and rationale behind the decisions, each process started anew. Amongst those interviewed, this was recognised as an important lost opportunity.

Knowledge and understanding of the legislature as a whole: Ultimately, policies are finalised and endorsed by the legislature as a whole through the National Assembly. Therefore, final policy decisions are vulnerable to the politics that is inherent to parliaments. According to interview respondents, the level of understanding of the realities of the sector by members of Parliament had significant bearing on the final document. An example frequently cited by interviewees was that of compensation. In 2013, despite the dialogue and debate that had already taken place, changes were made in Parliament to the clauses on compensation to raise the levels to be paid out. A number of interviewees felt that this was a political decision pushed forward by members of Parliament in response to pressures from their constituencies. Interviewees also pointed out that because this was unrealistic and unimplementable, it has significantly hindered the performance of the Act and affected the level of public support that the Act originally had. ${ }^{4}$

\section{Reflecting on, and learning from, the experience of the review of Kenya's WCMA 2013}

\section{How context and intervention influenced use of evidence}

The changes that occurred as a result of the WCMA 2013 review process occurred within a particular context and because a set of deliberate interventions 
were applied which triggered change mechanisms (such as building trust, commitment, confidence, etc.). These changes were changes in capability, opportunity or motivation (immediate outcomes) which ultimately brought about changes in policy and practice (wider outcomes).

The context included a constitution that had recently been revised and a requirement that all legislation in the country be aligned to it. Furthermore, a poaching crisis had led to high levels of international and national attention on the sector, adding to the sense of urgency. Finally, the timing was right. Elections had been held and a new government was in place with the space to engage in debate and discussion.

Evidence came in multiple forms and from multiple sources. The evidence included verbal and written submissions providing arguments and recommendations for changes to the Act, drawing on experience, published research, and grey literature. This was consolidated by the PRS who also gathered additional evidence and prepared briefs on specific topics, such as experiences from other countries. Multiple interventions were used to ensure that citizens were willing and able to actively engage and that the evidence provided and gathered was reflected upon and utilised by the Committee.

Interventions used by the Committee as well as different stakeholders and actors included convening of dialogue and debates involving policy makers, experts and practitioners (such as breakfast meetings); negotiated submission of joint statements by CSOs; one-to-one meetings to manage influence and conflict; the use of templates and structured processes to ensure that evidence was submitted in an organised manner and in direct response to the Act; and proactive outreach and engagement with stakeholders outside of the city, particularly local communities living in remote, wildlife-rich areas.

As a consequence, the spaces to ensure that the voices of all citizens were heard equally were strengthened, allowing for building and strengthening of trust and relationships. This enabled the participating stakeholders to better understand the perspectives, challenges and realities of one another as well as the wildlife sector. Policy makers received information in a manageable manner which enabled them to understand and relate the evidence to specific policy changes.

The outcomes that emerged included an increased motivation by civil society to engage in policy-making processes and by government to continue to gather evidence to address continued policy challenges. The experiences and relationships developed also increased opportunities for stakeholders to engage in policy-making processes in the country, providing research evidence and views. Furthermore, it led to increased capabilities including skills and tools for government to manage participatory processes, and an improved understanding of the realities and challenges of the sector and different stakeholder groups.

The Act itself was revised and many felt that it reflected their submissions and inputs. This ultimately led to changes in practice and policy in the sector, which continue to unfold today with the development of the policy and regulations. 


\section{Practical considerations around public participation and the role of Parliament}

\section{Important ingredients for effective engagement and participation}

The will from all parties to engage in a constructive manner and an enabling environment (such as appropriate timing and supportive legislation) are absolutely essential but are, in themselves, unlikely to result in effective public participation for policy making.

From the experiences of the WCMA 2013 review process, building blocks for an effective process include the following:

1 Guidelines and regulations to ensure best practice for all stages of the process;

2 Shared understanding of policy-making processes within the country;

3 Positive relationships and trust amongst stakeholders and actors involved;

4 Appropriate communication strategies and tools to convey and receive information with and amongst different types of stakeholders and actors;

5 Knowledge management processes and mechanisms to gather, organise and share information in a manner that can be accessed and utilised by the stakeholders involved.

A number of these building blocks take time to establish (for example, positive relationships and trust). As such, participatory and engagement processes should ideally be normalised as part of institutional culture (government and non-governmental).

We need to talk about wildlife ownership, rights and benefits and make these dialogues routine occurrences, and have them led by the government.

(Respondent 5 - Government)

Roles and responsibilities-Remembering the principles of form and function

Ensuring that public participation contributes to a robust policy-making process is highly dependent on multiple functions and roles being carried out successfully. Examples of functions and roles include acquiring and supplying evidence, demanding and using evidence for decision making, and brokering and facilitation between suppliers and users. Ensuring that the right skills and knowledge are in place is as important as is being cognisant of shortcomings and mitigating for associated risks.

Politicians like evidence - but people need to understand that it is their [the politicians'] purview to interpret the facts!

(Respondent 12 - Government) 


\section{The impact of leadership}

The right leadership was absolutely critical in the complex context in which the WCMA 2013 review process took place, with its turbulent history and multiplicity of values, beliefs and needs. In this case, the leadership comprised two champions (the Cabinet secretary of the MEWNR and the chair of the DCENR) who worked together to navigate the review through to its conclusion. Leadership characteristics identified as being instrumental in enabling them to do so included the following:

- Trusted and respected individuals

- Positive track records in policy making and in the sector

- Knowledge of the realities of the sector

- Established relationships and networks

- Political savvy with abilities to understand and navigate politics and power.

\section{Some final thoughts on public participation in policy making}

The value of citizen engagement and public participation in the revision of the Act in 2013 was unquestioned during this study. It was said to have resulted in ownership of the Act that was vital to its progression through to Parliament and final enactment. However, it was also recognised that reliance on contributions from citizens and the wider public alone carries significant risk. Individuals involved in this study pointed out that all actors and groups have agendas and biases. In the case of the wildlife sector in Kenya, these biases are often deeply entrenched and difficult to shift. It was noted by respondents that there were tendencies to selectively utilise research and other forms of evidence to argue for their positions. At the same time, issues falling outside of these interests tended to be ignored. This was said to be partially attributable to the limited bandwidth available to effectively engage in all debates. In addition, individuals pointed out that there are tangible risks associated with lobbying and advocacy, particularly when in opposition to influential actors (such as donors and government). These risks are only likely to be taken in relation to issues of utmost importance and where the stakes are high. The wildlife sector in Kenya is driven by strong ideological values which resulted in lot of noise coming through from social media and fake news with multiple emotional as well as science-based arguments (Respondent 12 - Government).

Ultimately, therefore, there was consensus amongst those contributing to the study that public participation was invaluable and essential, yet insufficient. It was felt that there should have been better use of multiple sources and types of evidence, including independent research.

These experiences, including the successes and challenges, generated a wealth of lessons and insights which have continued to strengthen participation in policy and decision making in Kenya. It is hoped that these lessons will be of 
value to other countries across Africa seeking to strengthen their own development processes by better involving citizens.

\section{Notes}

1 The term 'conservancy' was first used in 1995 with the establishment of the Lewa Wildlife Conservancy (a private conservancy) and Namunyak Community Conservancy.

2 www.theguardian.com/environment/2013/mar/06/ivory-poaching-sanctions-cites, accessed December 21, 2018.

3 The highest number of conservancies were established in 2013, at the time that WCMAA 2013 was being reviewed and KWCA was established (Kenya Wildlife Conservancies Association, 2016).

4 In the financial year 2013/14, a total of KES 214 million ( USD 2 million) was released to 3,215 claimants, with 363 being death cases and 2,888 injury cases. In the financial year 2014/2015, no compensation funds were released, although a total of 140 death cases were recorded by KWS as the Service was awaiting the launch of the County Wildlife Conservation and Compensation Committees (Ministry of Environment, Water and Natural Resources, 2015).

\section{References}

Anyonge-Bashir, M. and Udoto, P. 2012. Beyond philanthropy: Community nature-based enterprises as a basis for wildlife conservation. The George Wright Forum, 29(1), 67-73. Retrieved from JSTOR.

Barrow, E.G.C. and Fabricius, C. 2002. Do rural people really benefit from protected areas Rhetoric or reality? Parks, 12(2), 67-79.

Barrow, E.G.C., Gichohi, H. and Infield, M. 2000. Rhetoric or reality? A review of community conservation policy and practice in East Africa. London: International Institute for Environment and Development and International Union for Conservation of Nature.

The Clerk of the National Assembly. 2017. Public participation in the legislative process. Fact sheet No. 27. The National Assembly of Kenya.

Draman, R., Titriku, A., Lampo, I., Hayter, E. and Holden, K. 2017. Evidence in African parliaments. Oxford: INASP.

Kabiri, N. 2010a. Historic and contemporary struggles for a local wildlife governance regime in Kenya. In Community rights, conservation and contested land: The politics of natural resource governance in Africa. https://doi.org/10.4324/9781849775052

Kabiri, N. 2010b. The political economy of wildlife conservation and decline in Kenya. Journal of Environment and Development. https://doi.org/10.1177/1070496510384463

Kahumbu, P., Karani, J. and Muriu, E. 2017. On the right path? An analysis of Kenya's law enforcement response to wildife crime (No. 2016 \& 2017). WildlifeDirect.

Kenya. 1975. Statement on future wildlife management policy in Kenya. Retrieved from https:// books.google.co.ke/books?id=NmBJGwAACAAJ

Kenya Wildlife Conservancies Association. 2016. State of wildlife conservancies in Kenya report 2016. Nairobi: Kenya Wildlife Conservancies Association (KWCA).

Ministry of Environment, Water and Natural Resources. 2015. Status Report on the compensation of victims of human-wildlife conflict, and alleged irregularity in the recruitment of Kenya Wildife Service Rangers and efforts by KWS in the fight against poaching of elephants and rhinos.

Nelson, F. (ed.). 2010. Community rights, conservation and contested land: The politics of natural resource governance in Africa. London: Earthscan. 
Norton-Griffiths, M. 2010. The growing involvement of foreign NGOs in setting policy agendas and political decision-making in Africa. Economic Affairs, 30(3), 29-34. https://doi. org/10.1111/j.1468-0270.2010.02018.x

Republic of Kenya (RoK). 2014. The wildlife conservation and management act. kenyalaw.org/ lex//index.xql.

Republic of Kenya (RoK), K.N.A. n.d. Report on the consideration of the wildlife conservation and management bill, 2013. The fourth report of the first session.

Western, D. 2000. Conservation in a human-dominated world. Issues in Science and Technology, 16(3). https://doi.org/10.1017/CBO9781139047791.010

Western, D., Waithaka, J. and Kamanga, J. 2015. Finding space for wildlife beyond national parks and reducing conflict through community-based conservation: The Kenya experience. Parks, 21(1), 51-62. https://doi.org/10.2305/IUCN.CH.2014.PARKS-21-1DW.en 